\title{
A CHANGING CHILD IN A CHANGING WORLD: PSYCHOLOGICAL AND EDUCATIONAL PROBLEMS OF THE NEW SCHOOL
}

\author{
David I.Feldstein \\ Russian Academy of Education \\ Moscow
}

\begin{abstract}
The article is devoted to a number of urgent problems of mental and physical health of people who live in the global community. How we understand what is the world around us, what kind of society we live in and what are behavioural patterns and developmental features in the contemporary situation, and what the requirements of this society are. Changes in the modern child are influenced by an intense evolutionary self-development of modern man. Special attention should be paid to the development of science on the whole and psychological, psychophysiological, psychological and didactic branches in particular whose basis are stipulated in the textbooks and manuals of a qualitatively new generation.
\end{abstract}

Keywords: psychology, education, New School, socialization.

In his Address to the Federal Assembly of the Russian Federation (November 2009) Dmitry Medvedev, when speaking of "Our New School" national educational programme, set a crucial goal which consists in disclosing abilities of each student and nurturing him/her as a personality ready for life in the modern world. Unfortunately, despite the huge number of works of economists, philosophers, sociologists, historians, who designate it as a global community, speculate on the transition to postcivilization, neosphere, anthropogenic civilization, and draw attention to civilization breakdown, the meaning of our world is still not disclosed.

In spite of the fact that the human development and functioning have undergone changes in this changing world, we know even less about the man and changes in him.

Despite the diversity of the researches, in practice we can deal only with contradictory data, observations or views, which fix the real chang- 
es. We are faced with the difficult situation of development of a contemporary human individual.

For example, on the one hand, the growth of self-awareness of a human being and development of self-critical thinking are being traced and indicated. On the other hand, uncertainty, tension and anxiety come to the fore. Instability of social, economic and ideological situation is discrediting most moral values which cause immense psychological stress. The latter influences mental and physical health of people who live in the global community. These factors make people passive and indifferent.

In short, nowadays social and psychological sphere have obviously changed. This can be objectively related to ongoing changes in cultural and historical environment. According L.S. Vygotsky, genius of the Russian psychology, environment acts "in the sense of personal development and specific human characteristics, not as furnishings, but serves as a source of development."

Therefore, there arises a problem of comprehending the environment of the contemporary person. The problem focuses on how we understand what is the world around us, what kind of society we live in and what are behavioural patterns and developmental features in the contemporary situation, and what the requirements of this society are. In this connection it is important to quote Abraham Maslow, American psychologist: "Every age but ours has had its model, its ideal ... - the saint, the hero, the gentleman, the knight, the mystic. About all we have left is the welladjusted man without problems, a very pale and doubtful substitute."

The substitute is more than ever doubtful in the developing society, within the significant shifts in interpersonal, intergroup relations of human individuals, including family relationships at work and their general attitude to work.

We find it important to unveil the nature of mentality change, value guides, dramatic changes of cognitive and emotional sphere of people, accompanied by, inter alia, implementation of behavioural patterns which are alien to Russian culture, the consumerism, increasing indifference to the communication and, what is very alarming, general and individual psychological alienation of the adults from children, which is generating a risk of deteriorating the entire system of cultural and historical inheritance.

Two or three decades ago a child belonged mainly to a small group or a social community such as a family, a class, a group of peers, Pio- 
neer and Komsomol organizations, but always with a clear attachment to a particular adult person. Nowadays a child is placed in a completely new situation with broken boundaries. While at kindergarten and junior school (Russian preschool), a child finds himself/herself submerged in a boundless social space.

A child's mind is influenced by the chaotic flow of information coming from the TV, the Internet, which blocks the knowledge obtained from parents, educators and teachers, and also opens up a boundless area for various forms of relationships, ties and activities.

Moreover, this information is presented unsystematically and illogically being the form of intrusion into both a child's life and the process of his/her development.

Specific data collected by scientists show (here I provide research materials conducted by the RAO Psychological Institute, Moscow Psychological Pedagogical University, Faculty of Psychology of Lomonosov Moscow State University, Institute of Psychology of Sciences, Humanities and Arts Institute of the Nizhny Novgorod Architectural and Civil Engineering) that the change of the historical situation has stimulated the qualitative mental, physiological and personality changes of the contemporary child.

Among the factors that determine these changes we can first and foremost name market relations applied to all spheres of life and ethics of the market, which reinforce the children's values of consumption, as well as adoption, which removes the child from the cultural traditions of society and its history. Secondly, we deal with marginalization, i.e. unequal access to educational resources in big cities and small towns, increasing deviancy, the desire of parents to restrict the child's freedom and autonomy. Under the influence of these and other factors we are faced with such phenomena as medicalization, which consists in the fact that children are treated as if they were adults, with extensive use of antidepressants for aggressive children.

This subsequently causes higher levels of anxiety and fears, and in some cases even high level of aggression under the influence of militarization and computer games, which reduce the children's control over their own behaviour and consequently cause addiction.

The sphere of relations development between children is characterized by such a phenomenon as mobilization, which consists in the fact that teenagers are already voicing their own world view, their own posi- 
tion to child life versus adult life. They are developing a variety of informal networks that turn to be quite appropriate for their self-expression, scandalous and challenging behaviour, and demonstrating their attitude to the environment. Unfortunately, many of these children join countercultural communities, demonstrate asocial and antisocial judgements.

I do not mean only Satanists, punks, metalheads, whose values dwell on the principles of chaos, anarchy, vandalism, psychotropic agents abuse, which often lead them to the criminal path, but I am also talking about the most popular movement in today Russia such as Emo (Emo Kids) which embrace children from the age of 15 and older. They are characterized by willfulness, learned helplessness, change of mood, infantile behaviour. However, it should be admitted that we are quite aware of the social situation and the new features of the developmental process of the contemporary child.

The high necessity to thoroughly examine this problem is dictated by unfavourable prognosis for further changes in the social mental development and in particular in the development of the child's personality. The perspectives are supported by weakened conditions which display the potential to counter the negative influence.

These include low level of parental motivation, poor command of communication skills in parents in regard with children, poor organization of child's leisure and daily schedule.

Moreover, a significant number of parents apply their multiple failures in their family life, professional sphere and also personal problems to the child who is experiencing difficulties being submerged in the atmosphere of insolvency, failure, helplessness and hopelessness.

There is a kind of "inheritance" of family mishaps and parental failures.

Thus, a child is deprived of the sense of success since early age; his/ her confidence is dramatically undermined.

As a result, today children and adolescents, who are characterized by commitment to adult values, do not want to grow up, as they indirectly inherit the distrust of the outer world, especially of the adults.

We are having a child of 2010, whether he/she is an infant, preschooler, junior school student, teenager, high school student, who manifests efficient mechanisms of consciousness and thinking, that are strikingly different not only from the "child", who was described the john Amos Comenius and Pestalozzi, Ushinskii and Pirogov, Zazzo and Piaget, Ko- 
rchak and other great schoolmasters of the past, but also he/she is qualitatively different from a child of the 1990s.

The child was not better or worse than their peers 20 years ago, he/ she is simply a different child! There is a regular situation whose specific features were described by Daniel B. Elkonin, "Childhood does not only lengthen but also qualitatively changes both the structure and characteristics of all of its stages... Stages, which are 'below' in each new historical period, are significantly transformed by their psychological traits, their role in the entire development of children"... "The matter is that the process of historical development of the child is not merely added by another stage, but in the fact that the former stages change qualitatively."

And in the present situation of historically significant changes in the society the changes of the modern child are clearly observed.

1. In recent five years (2005 to 2009) cognitive development of preschool children has dramatically decreased. For example, according to 2006-2007 estimates, linear visual thinking of preschoolers was "average", while in 2009 it was estimated as "extremely poor". According to 2006-2007 data, structural visual thinking was estimated as "good", and in 2009 it is evaluated as "average". Other components of cognitive development are estimated in accordance with the same trend. So the development of divergent thinking (creativity) has decreased from "good" level to "poor" one.

2. Children are not as energetic as they used to be, their desire to be active has decreased. And vice versa their emotional discomfort has increased.

3. It is observed that the range of topics for role-playing games of preschool children is restricted to only a few ones, which leads to underdevelopment of motivational requirements of the child and his or her will and volition.

4. Research of cognitive abilities of senior preschoolers emphasizes extremely low level of children's capacities that require retention of internal rules and operate in terms of images. If the 1970s it was recognized as age norm, but today only about $10 \%$ of children cope with the operations assigned.

Undeveloped interior operational sphere and a reduced level of child curiosity and imagination have been recorded. Children can hardly cope with those operations which were available for their counterparts three decades ago. 
5. Attention is drawn to underdeveloped manual dexterity of senior preschoolers, who also lack graphic skills, which manifests not only the absence of graphic motor skills, but it also points out that certain brain structures which are responsible for the overall arbitrariness are underdeveloped.

The scarce of arbitrariness, both mental and motor ones of preschool children, is one of the most disturbing factors clearly identified by scientists of our academy.

6 . Insufficient social competence of $25 \%$ of primary school children, helplessness in regard with peers, inability to resolve regular conflict situations are widely observed. At the same time a dangerous trend within which more than $30 \%$ of independent solutions proposed by children are of aggressive character has been traced.

7. Children's obsession with television from infant age is alarming. According to the American scientists, schoolchildren watch TV 10-12 thousand hours since early school age. According to the Institute of Sociology of the Russian Academy of Sciences, more than $60 \%$ of parents spend leisure time with the child in front of TV. Every tenth preschooler spends all his/her free time in front of the TV set. As a result a child is permanently experiencing the desire to be stimulated by the TV screen, with his/her own activity being reduced. TV screen dependency leads to an inability to concentrate on any sort of occupation, lack of interest, hyperactivity, increased distraction. Such children are under the spell of constant external stimulation, which they are accustomed to get from the screen. They experience difficulties in listening and reading: they understand separate words and short sentences, but they cannot understand them all together in one text and do not understand the text as a whole. Children are losing the ability and desire to occupy themselves with any sort of activity. They are not interested in communicating with each other. They prefer to push a button and to be entertained by the flickering pictures.

8 . The adverse trend is the reduction of communication between children, including even teenagers who do not communicate a lot with their peers. Tendency to loneliness, aloof, low level of communicative competence are widely observed. Recent research show that in the early 1990's the adolescents were characterized by the state of loneliness, but anxiety was in the fourth or in the fifth places. As for 2009 research anxiety of 12-15-year-olders was in the second place, which was doubled 
by the sense of abandonment, emptiness, confusion, lack of self-confidence.

9. The number of children who experience emotional problems, who are submerged with affect state because of the constant feeling of insecurity, lack of support by close environment and a feeling of helplessness is increasing.

These children are vulnerable and extremely sensitive to the alleged offense, and they overreact to the attitude of others to them. All these factors and also their ability to remember mostly negative events lead to the accumulation of negative emotional experience, which complies with the principle of "vicious circle of psychological misery" and finds its expression in a relatively stable state of anxiety. At all stages of ontogenetic development, emergence and consolidation of anxiety, as a sustainable mental state, is associated with the unsatisfied desires at every stage of the human development.

10. Despite continuing morphofunctional maturation of the neural apparatus of the cerebral cortex in relation to the shifts of neuroendocrine puberty, adolescents survive regressive changes in the brain which is responsible for cognitive activity, while the increased activity of subcortical structures conditioned by hormonal processes leads to the deterioration of arbitrary regulation mechanisms. Selective attention ability is reduced, ability to select significant information decreases, working memory processes are restricted. There is a contradiction between cerebral mechanisms, which deal with the cognitive processes, and awareness of their adultness and independency.

11. Observation of the dynamics of the children's physical development reveals a trend of progressive reduction in the rate of longitudinal growth, the rise of asthenia stature, retarded growth of muscles.

12. There is a large group of children, who are characterized by negative and problematic mental development throughout ontogenetic stages. Thus, there is a tendency of major forms of mental diseases among children to increase by $10-15 \%$ every ten years. It is neuropsychiatric diseases that cause $70 \%$ of children's disability. And approximately $20 \%$ of children are observed to suffer from minimal brain disfunction. There has appeared a category of children, which in the accordance with neuropsychological performance should be considered a "border between norm and pathology". The category increases dramatically, and it is starting to dominate in some regions. Psychological problems are ob- 
served here in the field of: a) clinical forms of violations, b) border states, and c) subnormative development options.

13. There is a great number of children with disabilities, whose general underdevelopment of mental (mental retardation) is observed with $22.5 \%$ of children, and disharmonious development (psychopathy) is observed with $26.5 \%$ of them.

14. And thanks God, the category which is permanently increasing, consists of the gifted children. Among those there are children with highly developed thinking, children who are able to influence other people, i.e. leaders, children who can turn their hands to almost everything, children with visual thinking, i.e. creative children, and children with motor ability.

15. It is a significant fact that the primary activity of modern adolescents is not entertainment, but search for the meaning of life. Their criticism in relation to adults is increasing, their social development is characterized by new features. The observed outburst of individualism of teenagers, their commitment to the desire to be distinct from others, the formation and adoption of its unique "I" are contradicting with their development, for they are socially oriented figures.

16. The values of children, adolescents, young adults have changed dramatically in comparison with mid-1990s and early 2000s. Starting with 2007 the intellectual (first place), volitional (second place) and somatic (third place) values come to the fore. In their understanding, education, perseverance and determination are focused on the high level of achievements; they also think that good health and presentable appearance are especially important. But this is very troubling that such emotional and moral values as sensitivity, tolerance, empathy make the last row of this hierarchy. There is the negative dynamics of cultural and social values of schoolchildren.

However, changes in the modern child are influenced not only by social and cultural processes, which have also transformed the society, but also by an intense evolutionary self-development of modern man, that can be found in morphological changes, i.e. the so-called secular trends as asthenia, deceleration, left-handedness, juvenilization, gracilization and androgony, accompanied by a set of psychological properties. In particular, we can observe a high degree of creative abilities, less extraversion, greater self-sufficiency and independence of thought in children. 
In this connection, the thing is not only in the fact that the current generation of humans is accelerating the previous ones and manifest a number of new capacities. Here we do not mean unusual messiah children, or indigo children, who display unusual talents, and are considered a unique phenomenon, but we mean the entire population of today's children, and we are examining the changes in their perception, attention, memory, consciousness, thinking, orientation, etc. We are witnessing the shift of childhood age limit, which is associated with the process of retardation.

Educators cannot ignore the fact that nowadays children are not so early to pass through two growth-jumps or two crisis periods of development than their predecessors.

According to recent research data, the first jump called adolescent growth spurt does not refer to preschool age (6-6,5 years) as it was 13 years ago, but now it is correspondent with primary school age (7 to 8 years). In this connection, it is emphasized that in the first and perhaps even in second school grade teaching material must be presented to children in the form of games. At the same time retarded children perform significantly higher intellectual abilities, while their lack of intellectual demand causes retardation of the intellectual development, and also intellectual deprivation, or "mental hunger" - a condition which is consequented by delinquent behaviour, drug addiction, computer games addiction and other pathological distortions.

The second jump is called the pubertal spurt and associated with puberty period. It has also shifted from the fifth or sixth grades to the eighth or ninth grades for the girls and the nine or ten grades for the boys. Among other reasons different in nature, which can give us the answer to the question, why we are now observing the improved intelligence in the entire population of children. Comparative studies convince us that every five years, child's scores on IQ tests increase by approximately one point, which is the indicator of unusually rapid psychological development. This certainly means that evolutionarily less advanced children or children retarded in the rate of evolution have been going hand in hand with advanced phylogenetical human samples throughout the evolution of intelligence and the evolution of morphological and psychological traits of human beings.

However, according to recent data, from $50 \%$ to $55 \%$ of the senior preschoolers and primary school children in big cities of Russia score 
above 115 points on IQ tests, which incidentally raises the specter of "bias", placing greater emphasis on the intellectual development of children at the expense of social and personal development. Among the most important causal factors that have a tremendous impact on the physical, mental, intellectual and emotional development of children there is an intense flow of information, especially television and the Internet.

Modern man has created this tool, and it has broken the borders of the new cultural space. But he must learn how to use it for the sake of good aims with the active participation of the psychological and educational science, for we are already experiencing the negative effect of mass media. The negative effect is observed in the social anomie, i.e. the breakdown of social norms and values with other systems underdeveloped, and accompanied by cultural deprivation. On the one hand, it is also understood as restriction, and, on the other hand, we deal with cultural deprivation, i.e. limited access to spiritual resources and opportunities which are required to meet children's basic needs for their proper development, with its roots going deep into human cultural experience.

And here the educators and psychologists are faced with the problem of searching the ways of creating cultural attitude toward the Internet and television. In fact, the Internet represents a new cultural space with its own special language, special content, distinctive instructing methods and suggestive technologies which are impossible to monitor. It is important to study those programmes that television offer children, and great importance is drawn to the psychological and educational methods in the entire process of education. Our goal is not to blackball entertainers, producers, and television in general, but to identify ways, and possibilities of building interactive relations with the powerful phenomenon of television. It is clear that we cannot imagine a modern child without a virtual screen, be it a television screen, a video screen, a computer screen, or a cell phone screen.

The screen concept, penetrating into the child's mind by means of optical effects and images, does not just the instrument which has the power to implant new values and needs in children, but also to transform them.

In the world of fast changing information, adults have ceased to be authoritative conductors for children in the maze of knowledge. As the 
electronic media have blurred the boundaries between them, the curiosity is replaced by cynicism, self-conceitedness or arrogance. Children do not focus on the authority of adults, but on the information that comes out of "nowhere".

There arises a problem of studying not only the content of programs, but also the impact of speed, rhythms and flickering pictures of television on mental, psychological and physiological development of the child.

Actually, we are faced with changes in the sphere of childhood. However, we, as teachers, psychologists and researchers, do not simply state or detect these changes, but also identify their preconditions, scope, nature and contradictions in them. We search for roots not only in the impersonal conditioning factors, but also in children's self-development throughout the ontogenetic process, and consequently we reveal the essential features of ontogeny of the modern world.

Educational researchers, on the whole, and the scientists of the Russian Academy of Education, in particular, are brooding on modern childhood and prospects of its development. It is important to capture changes in basic features of the childhood, its developmental characteristics and transitions of developmental stages.

We are the ones who are obliged to detect what is changing in a child under the influence of social and cultural shifts and what remains invariant in the norm of his/her development. The recent data record unevenness of scrutiny, and contradictions in the resulting characteristics. This requires more sophisticated methodological approaches, application of psychological, educational, psychophysiological and neuropsychological research including comparative studies that, in particular, clarify innovations in different areas of psychological studies (cognitive, motivational, emotional). It is extremely important to carefully analyse the changes in the development of consciousness and self-consciousness of children, revealing features of perception, memory, thinking, identifying the nature and consequences of their brainwork. It is necessary to catch the changing tendency of child's development.

In this regard, the primary task is to develop and validate diagnostic methods both psychological and educational. It is next to impossible to continue using the techniques created 50-80 years ago, and more over to apply them to social cultural situation other than they were created for. Research aimed at building new tools for diagnosis should be prioritized.We are expected to determine the prospects of child development 
in contemporary society, and also establish priorities in child development at different stages of ontogenetic process, which directly relates to the identification of psychological and educational organization of today school.

It is well-known that the role of school in contemporary conditions is more than ever growing and changing. By this we identify the responsibility of psychological science, which is obliged to search goals, objectives, principles of organization, types of information presentation, focusing not only on the amount of knowledge but also on the disclosure of skills and developing children's ability to think. According to Friedrich Nietzsche, "Reason in school. Schooling has no more important task than to teach rigorous thinking, careful judgment, logical conclusions."

Nowadays we have extended and qualitatively changed the approach to knowledge, within which the truth remains unchallengeable - the entire system based on cultural views and scientific knowledge promotes freedom of thought and turns a "man of the crowd" into a true personality.

The researchers of the Russian Academy of Education, university professors, applicants of degrees in psychology and education should now be clearly focused on implementing of children's new opportunities, identifying their mental operations development and behavioural patterns, disclosing reserves and opportunities for reconstruction of the educational process, modeling creative situations without particular attachment to grade-level system, leading the search for new individual and collective forms of training, mobilizing capabilities which make the child responsible, determining ways of development of every child and also with particular attention to logical and conceptual thinking, the ability to perceive the world in all its manifestations and stimulating collaboration between teachers and students.

Nowadays special attention should be paid to the development of science on the whole and psychological, psychophysiological, psychological and didactic branches in particular whose basis are stipulated in the textbooks and manuals of a qualitatively new generation. These branches of science should be establishing relationships with advanced information technologies, including the Internet. It is important to identify possible combinations of the existing information pressure and an 
organized system of education for children, searching for psychological and methodological grounds of the education process in the contemporary conditions that require implementation of the new methods and mechanisms for developing selective attitude to information in children, adolescents, young adults, with particular focus on the skills of ranking knowledge in the process of self-attribution.

The necessity of basic research now comes to the fore not only for cognitive and social development of children but also for spiritual one. Great importance should be attached to the studies aimed at disclosing the inner world of the both child's general and individual experience, aspirations and doubts, including creativity, basic features of spiritual value acquisition and moral settings.

Thus, it is important to clearly understand what we are preparing a child for, be it competition, power or money. Or are we preparing a child to be responsible for himself/herself and other people, for the safety of life on the Earth, for encouraging him/her to human actions worthy of a human being?

Academic councils of universities and research institutes need to identify priority fields for interdisciplinary research, including the joint work of teachers and psychologists, physiologists and sociologists, specialists in psychogenetics and anthropologists, ethnographers and ecologists, demographers and economists.

Teachers, postgraduate students, doctoral students, doctoral candidates, laboratory assistants should be focused on the study of:

1) general patterns of cognitive processes in human beings at all stages of childhood;

2) identifying sensory capabilities of mental development at each developmental stage;

3) establishing age limits in knowledge acquisition, skills development and abilities development;

4) identifying principles of education and methodology of knowledge presentation, and eventually developing children's personal attitude to them;

5) determining conditions for the development of creative abilities, i.e. potential abilities of a child which will allow to solve the problems of innovative education, aimed at acculturation of each child; 
6) identifying mental development "reserves" of a contemporary child, ways of "reserves" accumulation, including opportunities to accelerate mental development through the introduction of computer technologies and computer science in school education;

7) clarifying the conditions which promote social maturity and responsibility;

8) determining psychological factors which influence beliefs and social values among adolescents and youth;

9) establishing psychological conditions for their socialization and self-identity when overcoming the negative effects in some representatives of the youth.

Here I have been able to touch briefly upon a number of urgent problems which are likely to be resolved if we unite our efforts. Unfortunately, major contemporary educational and psychological research, including Ph.D. and Sc.D. theses, do not go deep into the essence of the phenomenon under focus, and require long-term experiments and prolonged hard work. Please forgive my elevated style, but who can resolve the situation if not us? It is not our task - it is our responsibility. 